\title{
Development and Evaluation of Pendulum Type Impact Shear Test Apparatus
}

\author{
Dara Rooha Blessy*, Ammana Spandana, Vennela Gopaladas, \\ Payala Ravindrabharathi and Er. Ch. Sravan Kumar
}

Department of Farm Machinery and Power Engineering College of Agricultural Engineering, Kandi, Sangareddy, Professor Jayashankar Telangana State Agricultural University, Telangana, India

*Corresponding author:

\section{A B S T R A C T}

\begin{tabular}{|l|}
\hline K e y w o r d s \\
Sorghum stalks, \\
$\begin{array}{l}\text { Stalk girth, } \\
\text { Moisture content, } \\
\text { Cutting energy, etc. }\end{array}$ \\
\hline Article Info \\
\hline $\begin{array}{l}\text { Accepted: } \\
\text { 12 May } 2019 \\
\text { Available Online: } \\
\text { 10 June } 2019\end{array}$ \\
\hline \hline
\end{tabular}

\section{Keywords}

Sorghum stalks,

Stalk girth Cutting energy, etc.

Article Info

12 May 2019

10 June 2019
Cutting energy is one of the most important factors to design the types of grain combine and harvesters which harvests the agricultural crops. Aim is to determine the cutting energy, plays a vital role in lowering the energy consumption of grain combines and harvesters. Therefore, need for determining cutting energy is essential to redesign the harvesters. A pendulum type impact shear test apparatus was developed to calculate the energy requirement for cutting Sorghum stalks. It works on the principle of law of conservation of energy. The apparatus consisted of frame, pendulum, pointer, protractor, cutting blade and stalk holder. It was observed that the cutting energy of Sorghum stalks of 5,10 and $15 \mathrm{~mm}$ girths at three moisture contents $10 \pm 1 \%, 12 \pm 1 \%$ and $14 \pm 1 \%$ were 10373.21 MJ, 9877.54 MJ and 9449.66 MJ respectively. The results show that the optimum value of cutting energy was obtained at $14 \pm 1 \%$ moisture content. It was observed that there is a positive correlation between cutting energy and stalk girth and negative correlation between cutting energy and moisture content.

\section{Introduction}

Sorghum (Sorghum bicolor) is the world's fifth most important cereal crop after Rice, Wheat, Maize and Barley. India is the second largest producer of Sorghum in the world. The average annual production of Sorghum in India is 8.71 million tonnes. It is mostly cultivated in the semi-arid regions for fodder to feed the large cattle population of the country as well as to meet the demand of industrial application. The advantage of this cereal crop is it can be cultivated in both Kharif and Rabi seasons. Area under cultivation of Sorghum in India is around 9.5 million hectares. The yield of Sorghum per hectare in India is $840 \mathrm{~kg}$ per hectare. The average annual production of Sorghum in Telangana is about 961 thousand tonnes. Area under cultivation in Telangana is around 76 thousand hectares.

Grain Sorghum stalks left standing after harvest provides ground cover during the 
winter and also serves as an inexpensive source of forage for cattle to graze. Approximately $50-60 \%$ of the plant dry matter of grain Sorghum remains in the field after harvest. Green silage of Sorghum is harvested after picking tassel up. If Sorghum is harvested in phase of milky kernel state it will have high protein level, dry matter and nutrients.

The residue left after harvesting the tassel of Sorghum is said to be Sorghum stalk. It can be directly grazed by cattle or dried and used as fodder. It has also attracted some attention as a potential fuel source and as a biomass for fermentation or as a feedstock for cellulosic ethanol production. Sorghum biomass is densified to briquettes which are used as a fuel source, and have the average calorific value of $12.6 \mathrm{MJ} / \mathrm{kg}$.

The cutting of stalks is an important process in Sorghum harvesting. In olden days, traditional tools like cutlass, scythe, knife and hoe were used for cutting the stalks. Now-adays harvesting of Sorghum stalks is replaced by Sorghum harvesting machines.

But Sorghum which has been harvested manually by hand is proved to be an impediment to the expansion of its cultivation. Hence, there is a need to gear efforts towards bridging the gap between demand and production of Sorghum by developing simple tools and appropriate technology machines that fit the general objective of mechanization for increased food production.

The knowledge of energy required to cut Sorghum stalks is the basis for the design of a machine for harvesting of Sorghum crop. Therefore, it is pertinent to find the energy required to cut the Sorghum plant (Suleiman et al., 2012). Cutting energy in agricultural crops determines that how much energy is needed to cut stalks. Thereby harvesting machines and harvesters should be redesigned for lowering energy consumption. Consequently, fuel consumption and fuel cost of harvesters is reduced which is more helpful to farmers (Azadbakth et al., 2014). Therefore, in order to find the energy expended for cutting Sorghum stalks an attempt has been made with the following objectives.

To fabricate Pendulum Type Impact Shear Test Apparatus.

To calculate the energy required to cut the Sorghum stalks.

\section{Materials and Methods}

The research was conducted in order to determine the cutting energy of Sorghum stalks as a function of moisture content and stalk girth. More over the effect of moisture content and stalk girth on cutting energy were investigated.

\section{Constructional details}

The pendulum type impact shear test apparatus consists of following major components: main frame, pendulum, bench vice (stalk holder), angle indicator, protractor, blade (Fig. 1 and 2).

Two pillow block bearings were mounted on the top of the frame with nuts and bolts to hold the rotating shaft of the pendulum arm. Cutting blade could be mounted on the tip of the pendulum. A commercially available protractor with angular divisions was used for measuring the angular displacement also called dial. A pointer actuated by the pin provided on the axis of rotation of the pendulum showed the angle of swing of the pendulum on this graduated scale. It has a fixed bench vice for holding the stalks. 


\section{Experimental procedure}

A Pendulum Type Impact Shear Test Apparatus was fabricated and used in this study. It works on the principle of law of conservation of energy. A cutting blade was attached to the end of the pendulum arm and it was dropped from certain angles. Cutting is done when blade is in its lowest position, a pointer is connected to the backside of the arm and indicates the position of the angle indicator on a protractor graduated into degrees.

To obtain cutting energy requirement, pendulum arm was released from different angular positions like $70^{\circ}, 80^{\circ}, 90^{\circ}, 110^{\circ}, 120^{\circ}$ and $130^{\circ}$. Stalks of various girths 5,10 and 15 $\mathrm{mm}$ were positioned in the bench vice directly beneath the lowest position of the blade. There is a continuous exchange of the energy of the swinging arm from maximum potential energy, when the arm is at its extreme position (upswing) before it is released to swing down loosing potential energy and gaining kinetic energy when the arm is at equilibrium line. To impart enough energy to cut the stalk the pendulum is normally displaced to one side of the equilibrium position by an angular deflection, $\theta d$.

When the arm was released, it gains speed till it meets and cuts the stalk placed in the path of the knife. When dropped the pendulum arm was expected to oscillate to other side of the equilibrium arm and deflect to an angle, $\theta c$ which is normally less than $\theta d$ (due to frictional resistance in the parts and air resistance). Before and after cutting angles were noted. After each experiment, moisture content of stalks was determined. The experiment was conducted at three moisture contents i.e., $10 \pm 1 \%, 12 \pm 1 \%$ and $14 \pm 1 \%$. The experiment was replicated 3 times at three moisture contents and average cutting energy was calculated.

\section{Moisture content determination}

Moisture content was determined by drying samples in oven at $110^{\circ} \mathrm{C}$ for 1 hour (Alternative Sources of Energy, Rathore et $a l$. ,) and was expressed in wet basis. The loss in the weight of the sample was recorded and moisture content was calculated from the following equation.

$M C w b=\frac{\mathrm{wi}-\mathrm{wf}}{\mathrm{wi}} \times 100$

Where,

$M C w b=$ Moisture content on wet basis $\mathrm{w}_{\mathrm{i}}=$ Initial weight of the sample $(\mathrm{g}) \mathrm{w}_{\mathrm{f}}=$ Final weight of the sample $(\mathrm{g})$

\section{Cutting energy calculation}

Cutting energy is the energy which is required to cut agricultural crops. It was evaluated as a function of moisture content and stalk girth.

The energy dissipated in cutting a specimen is given by the following formula (Yiljep et al., 2005, Ananda Kumar and Sanjeeva Reddy, 2015).

$\mathrm{E}=\mathrm{W} \times \mathrm{R} \times\left(\cos \theta_{c}-\cos \theta_{d}\right) \times 10^{3}$

Where,

$\mathrm{E}=$ Cutting energy $(\mathrm{MJ})$

$\mathrm{W}=$ Total weight of pendulum arm $(\mathrm{N})$

$\mathrm{R}=$ Centre of gravity w.r.t rotation of pendulum $(\mathrm{m})$

$\mathrm{R}=\frac{\mathrm{b} d^{2}}{12}$

$\theta_{c^{-}}=$angular displacement of the pendulum after cut $\left(^{\circ}\right)$ 
$\theta_{d}=$ angular displacement of the pendulum before cut $\left({ }^{\circ}\right)$

\section{Results and Discussion}

\section{Effect of moisture content on cutting energy}

This test was conducted at moisture contents $10 \pm 1 \%, 12 \pm 1 \%$ and $14 \pm 1 \%$ with 5,10 and $15 \mathrm{~mm}$ stalk girths. It was observed that cutting energy of Sorghum stalks decreases with increase in moisture content as shown in Figure 3. Therefore, increase in moisture content leads to decrease in cutting energy of Sorghum stalks.

The reason is that at low moisture content i.e., in dry conditions the thickness of the Sorghum stalks has wooden state (Prasad and Gupta, 1975). So, more energy is required for cutting at low moisture content. From the
Statistical analysis, it was observed that the correlation coefficient (r) between moisture content and cutting energy was highly negatively significantly correlated.

\section{Effect of stalk girth on cutting energy}

The cutting energy of the Sorghum stalks at stalk girths of 5,10 and $15 \mathrm{~mm}$ with respect to moisture contents were presented in the Table 1. It was observed that the cutting energy required for cutting Sorghum stalks increased gradually as the diameter of the stalk increases. It is due to the full maturity of stalks, because in full mature stalks cellulose become compact and hard. So the force required to cut was increased as stalk girth increased (Dange et al., 2011). From the Statistical analysis, it was observed that the correlation coefficient(r) between moisture content and cutting energy was highly positively significantly correlated.
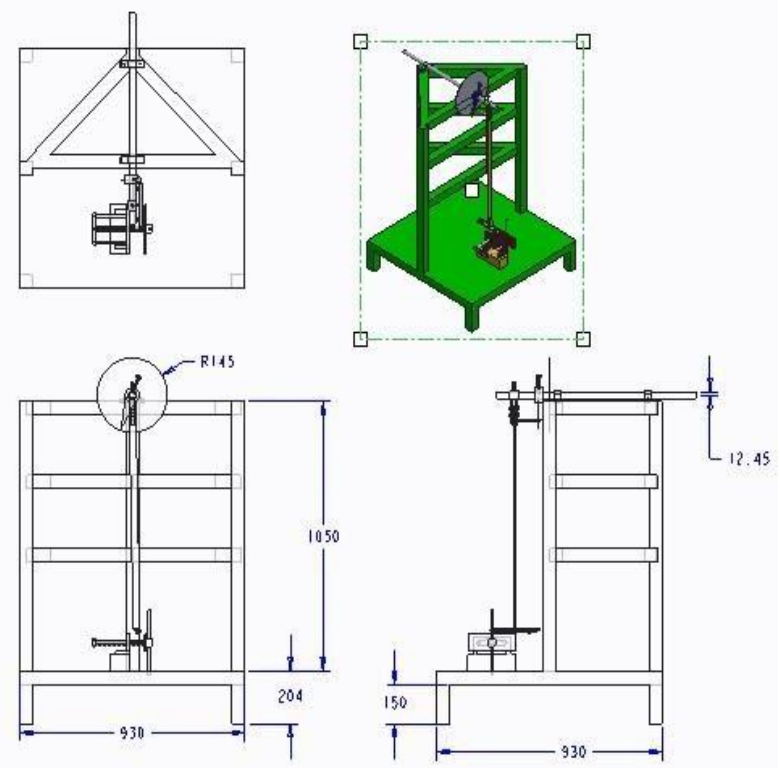

Fig. $12 \mathrm{D}$ view of pendulum type impact shear test apparatus

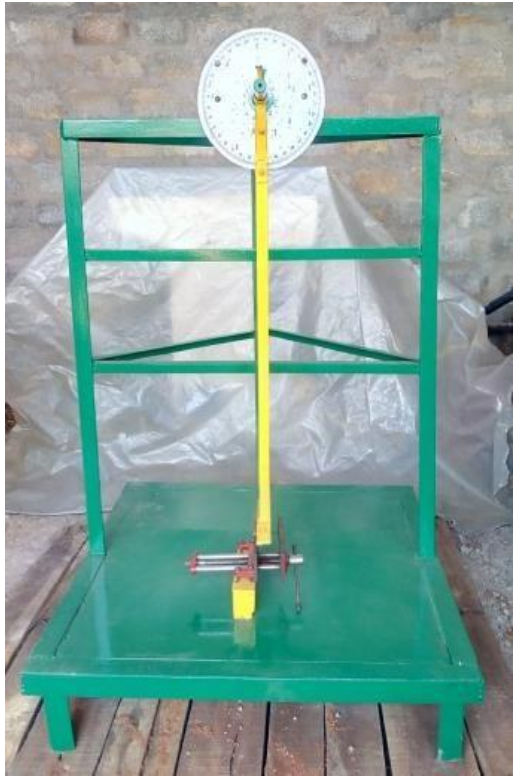

Fig. 2 Impact shear test apparatus

(All dimensions are in $\mathrm{mm}$ ) 


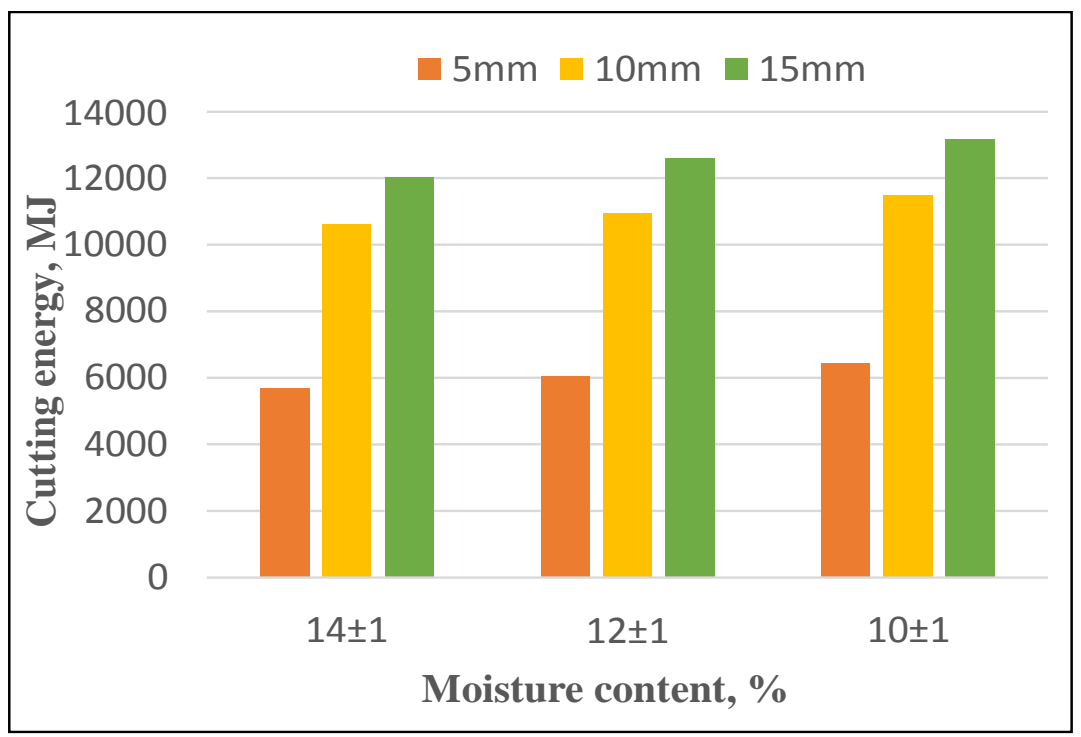

Fig. 3 Effect of stalk girth and moisture content on cutting energy

Table.1 Effect of stalk girth and moisture content on cutting energy

\begin{tabular}{|l|c|c|c|}
\hline \multirow{2}{*}{ Stalk girth, mm } & \multicolumn{3}{|c|}{ Moisture content, \% } \\
\cline { 2 - 4 } & $14 \pm 1$ & $12 \pm 1$ & $\mathbf{1 0 \pm 1}$ \\
\cline { 2 - 4 } & & Cutting energy, MJ \\
\hline $\mathbf{5}$ & 5694.75 & 6063.13 & $\mathbf{6 4 3 5 . 3 6}$ \\
\hline $\mathbf{1 0}$ & 10625.84 & 10963.53 & $\mathbf{1 1 5 0 2 . 6 9}$ \\
\hline $\mathbf{1 5}$ & $\mathbf{1 2 0 2 8 . 4 2}$ & $\mathbf{1 2 6 0 5 . 9 5}$ & $\mathbf{1 4 1 8 1 . 5 6}$ \\
\hline
\end{tabular}

Hence concluded in this study the effect of moisture content and stalk girth of Sorghum stalks on cutting energy was investigated. Results indicated that an increase in moisture content of stalk led to decrease in cutting energy, whereas an increase in stalk girth led to an increase in the cutting energy.

The cutting energy was found less at $14 \pm 1 \%$ moisture content for 5,10 and $15 \mathrm{~mm}$ stalk girths when compared with other two moisture contents i.e., $12 \pm 1 \%, 10 \pm 1 \%$.

The cutting energy was found to be less at 5 $\mathrm{mm}$ stalk girths when compared with $10 \mathrm{~mm}$ and $15 \mathrm{~mm}$ at moisture content of $14 \pm 1 \%$ than at $12 \pm 1 \%, 10 \pm 1 \%$. Therefore, it was concluded that cutting energy increases, as stalk girth increases.
This study finally helps in finding the cutting energy requirement for harvesting Sorghum stalks. Cutting energy determination helps in redesigning the harvesters which effects in lowering the fuel consumption. Hence it aids farmers in reducing the cost of cultivation of Sorghum crop.

\section{References}

Ananda Kumar, T., and Sanjeeva Reddy. "Bending and Cutting Characteristics of Maize Stalk Residue." Research Journal of Agricultural Sciences 6.5 (2015): 1136-1138.

Azadbakht, M., Esmaeilzadeh, E., \& Esmaeili-Shayan, M. (2015). Energy consumption during impact cutting of canola stalk as a function of moisture 
content and cutting height. Journal of the Saudi Society of Agricultural Sciences, 14(2), 147-152.

Dange, A. R., Thakare, S. K., and Rao, I. B. (2011). Cutting energy and force as required for Pigeon pea stems. Journal of Agricultural Technology, 7(6), 14851493.

Prasad, J., and Gupta, C. P. (1975). Mechanical properties of maize stalk as related to harvesting. Journal of Agricultural Engineering Research, 20(1), 79-87.

Prasanth Kumar, K., and Saravana Kumar, M. (2017). Development and Calibration of Pendulum Type Test Rig. International
Journal of Current Microbiology and Applied Sciences, 6(9), 1498-1503.

Rathore, N. S., Mathur, A.N., and Kothari, S. (2007). Alternative sources of energy.

Samaila, S., Al-Sharief, H. M., and Abdulkadir, S. A. (2012). Development of a tool to determine the energy required to cut and top sugarcane. AU Journal of Technology, 16(1).

Yiljep, Y. D., and Mohammed, U. S. (2005). Effect of knife velocity on cutting energy and efficiency during impact cutting of sorghum stalk. Agricultural Engineering International: CIGR Journal.

\section{How to cite this article:}

Dara Rooha Blessy, Ammana Spandana, Vennela Gopaladas, Payala Ravindrabharathi and Sravan Kumar, Er.Ch. 2019. Development and Evaluation of Pendulum Type Impact Shear Test Apparatus. Int.J.Curr.Microbiol.App.Sci. 8(06): 1436-1441. doi: https://doi.org/10.20546/ijcmas.2019.806.174 